\title{
Compras Estratégicas No Setor Público: Uma Revisão Sistemática Da Produção Nacional
}

\section{Strategic Purchases In The Public Sector: A Systematic Review Of The National Literature}

\author{
Walisson Alan Correia Almeida ${ }^{1}$, Patricia Guarnieri ${ }^{1}$, Luciana Goulart ${ }^{1}$, Raoni Fonseca Duarte ${ }^{1}$, Gisela Demo ${ }^{1}$ \\ ${ }^{1}$ Universidade de Brasília, UNB, Brasil. \\ Correspondência: Patricia Guarnieri. Campus Darcy Ribeiro, Sala 111-7, B1. 4, Asa Norte, CEP 70.910-900, \\ Brasília, DF, Brasil. Telefone: +55 (61) 3107-0749. E-mail: patguarnieri@gmail.com.
}

Recebido: 26 de julho de 2017 Aceito: 30 de setembro de 2018 Publicado: 28 de dezembro de 2018

DOI: http://dx.doi.org/10.21714/1679-18272018v16n2.p117-131

\begin{abstract}
Resumo
Desde o final da década de 1970, muitos autores têm evidenciado o caráter estratégico da função de compras para as organizações. No entanto, a pesquisa científica sobre o assunto tem se baseado, em grande parte, em estudos sobre o setor privado, ao passo que as compras estratégicas no setor público têm recebido relativamente pouca atenção acadêmica. Diante disso, o objetivo desta pesquisa é realizar uma revisão sistemática da produção nacional em relação a compras estratégicas no setor público. O estudo é de natureza descritiva, de abordagem qualitativa, e se utiliza da revisão sistemática da literatura como procedimento. Os resultados demonstram que a função de compras se torna mais estratégica em uma organização pública na medida em que esta cultiva competências relacionadas ao desenvolvimento sustentável, em seu tripé ambiental, social e econômico, e também ao uso otimizado de contratação eletrônica (e-procurement), aos critérios de seleção dos fornecedores, à indução da inovação e, em menor grau, à parceria interorganizacional. O presente trabalho contribui ao identificar uma agenda de pesquisa a partir das lacunas identificadas na literatura, auxiliando pesquisadores e gestores a direcionar seus esforços e a tomar decisões relativas à prática organizacional.
\end{abstract}

Palavras-chave: Compras estratégicas, Compras públicas, Organizações públicas.

\begin{abstract}
Since the late 1970s, many authors have demonstrated the strategic nature of purchasing function for organizations. However, scientific research on the subject has been largely based on studies of the private sector, while strategic purchases in the public sector has received relatively little academic attentionconstituting a gap. Therefore, the objective of this research is to develop a systematic review of the national literature concerning strategic purchases in the public sector. The results demonstrate that the purchasing function becomes more strategic in a public organization insofar as it cultivates related competences, especially the sustainable development on its environmental, social and economic dimensions, and also the optimum use of e-procurement, supplier selection criteria, innovation induction and, to a lesser extent, inter-organizational partnership. The present work contributes to identify a research agenda based on the gaps identified in the literature review, helping researchers and managers to direct their efforts and make decisions regarding organizational practice.
\end{abstract}

Keywords: Public procurement, Public organizations, Strategic procurement.

Esta obra está licenciada sob uma Licença Creative Commons Attribution 3.0

\section{Introdução}

Desde o final da década de 1970, muitos autores têm evidenciado a importância de encarar de forma estratégica a função de compras em empresas no setor privado (FARMER, 1978; FREEMAN; CAVINATO, 1990; KISER, 1976; MONCZKA, 1992; PEARSON; GRITZMACHER, 1990; RECK; LONG, 1988; SPEKMAN, 1989; SPEKMAN; HILL, 1980).

Em uma analogia muito apropriada, Cooper e Ellram (1993) comparam o gerenciamento da cadeia de suprimentos (supply chain management - SCM) a uma equipe de revezamento: mais valor competitivo é agregado quando cada componente sabe como se posicionar para a "troca do bastão". As autoras defendem que a função de compras é 
um componente fundamental para o sucesso do SCM, devendo assumir e desempenhar papel estratégico na concepção e implementação deste conceito (COOPER; ELLRAM, 1993).

Corroborando essa posição, a produção acadêmica sobre o assunto indica que as compras estratégicas têm impacto substancial sobre o desempenho das empresas (CARR; PEARSON, 2002; CARR; SMELTZER, 1997, 1999; CARTER; NARASIMHAN, 1996; CHEN; PAULRAJ; LADO, 2004; ELLRAM; CARR, 1994; GADDE; HÅKANSSON, 1994; NARASIMHAN; DAS, 2001; PAULRAJ; CHEN; FLYNN, 2006; SPEKMAN; KAMAUFF; SALMOND, 1994; WATTS; KIM; HAHN, 1995).

Segundo Carr e Pearson (2002), a função de compras pode ser descrita como estratégica, quando é proativa em relação aos objetivos da empresa, integrativa e tem um foco de longo prazo e como não-estratégica, quando é administrativa por natureza, reativa a outras funções, não integrativa e focada em questões de curto prazo ou.

Ocorre que os resultados de algumas pesquisas indicam que existem diferenças significativas entre a organização da área de compras dos setores público e privado, em especial devido ao papel que as contratações públicas desempenham na consecução de objetivos governamentais mais abrangentes do que a simples busca por lucro (ARLBJØRN; FREYTAG, 2012; JOHNSON; LEENDERS; MCCUE, 2003; MURRAY, 2001; ZHENG et al., 2007). A despeito de tais diferenças, o enfoque científico sobre o assunto tem se baseado, majoritariamente, em estudos sobre o setor privado, ao passo que as compras estratégicas no setor público têm recebido relativamente pouca atenção acadêmica, apesar de representarem uma parcela significativa dos gastos dos governos (WHITE et al., 2016).

Corroborando o interesse prático do assunto, é importante ressaltar que, no caso do Brasil, por exemplo, no ano de 2016, apenas os processos de compras dos órgãos da administração direta, autárquica e fundacional do poder executivo federal totalizaram R \$ 51,07 bilhões, conforme consulta realizada no Painel de Compras do Governo Federal (BRASIL, 2017), valor equivalente a $0,8 \%$ do produto interno bruto do país naquele ano (R\$ 6.266,9 bilhões). Não estão incluídos neste montante os gastos dos demais poderes (judiciário e legislativo) e de instituições dotadas de autonomia, tampouco as empresas públicas e as sociedades de economia mista pertencentes ao governo federal.

Ademais, do ponto de vista acadêmico, devem ser realçadas as contribuições de Murray $(1999 ; 2001)$ quanto à importância de pensar estrategicamente a função de compras para o setor público. Em seu artigo seminal, o autor demonstra que os objetivos estratégicos do governo são fundamentalmente diferentes dos de organizações do setor privado, motivo pelo qual os gestores de compras governamentais precisam aplicar abordagens de compras do setor privado, em um contexto diferente, e complementá-las com novas abordagens, que devem contribuir não só para a redução de custos e para a melhoria da qualidade e transferência de inovação, mas também para o desenvolvimento econômico local, melhorias ambientais e promoção da imagem da organização junto a atores externos (MURRAY, 1999).

Assim, considerando que se trata de um campo emergente, interessa saber como têm sido desenvolvidas as pesquisas sobre compras públicas estratégicas, o que se constitui em uma lacuna na literatura. Justificando essa constatação, Mogre, Lindgreen e Hingley (2017) enfatizam que, não obstante a importância das compras estratégicas no setor público, é certo que o conhecimento existente sobre o tema não está consolidado, demandando atenção adicional dos pesquisadores. Alinhados a essa percepção, White et al. (2016) afirmam que a função de compras deve ter um papel muito mais estratégico em organizações do setor público, em função das escolhas cada vez mais complexas de produtos, uso de tecnologia, questões ambientais e uma mudança no foco do preço para a agregação de valor do dinheiro gasto (value for money).

Desta forma, considerando o interesse prático e acadêmico sobre o assunto, além da inexistência de revisão de literatura abordando especificamente o tema das compras públicas estratégicas no Brasil, este artigo busca responder a seguinte questão de pesquisa: qual é o estado da arte nas publicações nacionais sobre o tema de compras públicas estratégicas?

Para responder esta questão, a pesquisa realiza uma revisão sistemática da produção nacional sobre compras estratégicas no setor público, utilizando-se o protocolo de Cronin, Ryan e Coughlan (2008). Para atingir este objetivo, foram selecionados para análise um total de 15 artigos publicados em periódicos de primeira linha, conforme classificação mais recente (quadriênio 2013-2016) do Sistema Qualis da Coordenação de Aperfeiçoamento de Pessoal de Nível Superior (Capes), com índice igual ou superior a B2.

\section{Referencial Teórico}

\subsection{Compras Estratégicas No Setor Privado}


Durante muito tempo, o conceito de compras estratégicas não atraiu a atenção de acadêmicos do campo, refletindo a opinião de que o papel da função de compras era mais reativo do que proativo,ou, que a função era meramente administrativa e operacional, ao invés de estratégica (FARMER, 1978).

De forma pioneira, Kiser (1976) alertou que a função de compras deve arcar com uma série de atribuições muito relevantes na organização, dentre elas, gerar soluções alternativas para problemas de aquisição, proteger a estrutura de custos da empresa, minimizar os custos de compras, assegurar suprimentos de longo alcance e manter boas relações com os fornecedores.

Farmer (1978) destacou que o objetivo do desenvolvimento de estratégias é permitir que a organização obtenha alguma vantagem competitiva e, neste contexto, a organização que ignora o potencial de contribuição estratégica da função de compras está, na realidade, deixando de lado essa fonte potencial de vantagem.

Com base em uma revisão de literatura pioneira acerca do tema, Ellram e Carr (1994) afirmaram que a função de compras desempenha um papel relevante quando incluída no planejamento estratégico e na implementação, no mesmo nível que outras áreas funcionais, e isso ocorre quando a importância da função é reconhecida, aceita e operacionalizada pela alta administração. Assim, a função de compras deve assumir maior importância dentro das organizações, sendo que esta evolução exige que a função de compras desenvolva novas competências e seja reconhecida como essencial para a estratégia organizacional (ELLRAM; CARR, 1994).

Dois estudos muito citados sobre o tema são de autoria de Chen, Paulraj e associados (2004; 2006). O primeiro trabalho enfatizou a contribuição das compras estratégicas para o desempenho financeiro das empresas e o grau com que elas contribuem para a gestão da relação entre compradores e fornecedores, por exemplo, por: i) promover relações de trabalho estreitas com um número limitado de fornecedores; ii) estimular a comunicação aberta entre parceiros da cadeia de suprimentos; e iii) desenvolver uma orientação estratégica de longo prazo para obter ganhos mútuos (CHEN; PAULRAJ; LADO, 2004). No segundo estudo, os autores concluíram que as compras estratégicas podem ter um profundo impacto no desempenho da cadeia de suprimentos, o que, subsequentemente, gera uma situação vantajosa tanto para a empresa compradora quanto para a fornecedora (PAULRAJ; CHEN; FLYNN, 2006).

Mais recentemente, Glock e Hochrein (2011) expuseram que o conceito de compras estratégicas pode ser definido como o processo de planejamento, implementação, avaliação e controle de decisões estratégicas e operacionais para direcionar todas as atividades da função de compras para oportunidades consistentes com a capacidade da empresa para atingir seus objetivos de longo prazo.

Destarte, Mogre et al. (2017) consideraram que a função de compras está, efetivamente, tornando-se mais estratégica e mais integrada com outras funções organizacionais. Além disso, observam que a função de compras também pode assumir um papel estratégico na mitigação dos efeitos negativos de riscos da cadeia de suprimentos, em face das recentes tendências de terceirização e globalização, que aumentaram os problemas de coordenação e controle e diminuíram a capacidade de resposta e a resiliência das cadeias de suprimentos aos riscos.

Não havendo dúvidas sobre sua relevância estratégica no setor privado, interessa saber qual o papel estratégico da função de compras no setor público, aspecto discutido na próxima seção.

\subsection{Compras Estratégicas No Setor Público}

Pode-se considerar que foi, principalmente, a partir das contribuições de Murray (1999) que se reconheceu que as estratégias de compras tradicionais do setor privado não são suficientes para as necessidades do setor público. Em seu artigo seminal, o autor procurou estabelecer a razão de ser do governo local, para depois apresentar conclusões significativas quanto ao papel estratégico que a função de compras deve procurar alcançar no setor público (MURRAY, 1999). Embora focado nos governos locais, acredita-se que os entendimentos do autor são aplicáveis para as organizações públicas em geral.

Partindo da premissa de que as estratégias funcionais derivam das estratégias corporativas da organização, o autor apresentou uma incisiva comparação entre as compras do setor privado e do governo local, concluindo que as estratégias de compras do setor privado são insuficientes para o governo local. Além disso, um estilo de compras que vá além das abordagens tradicionais deve proporcionar uma contribuição estratégica maior para as organizações do setor público (MURRAY, 1999).

Inicialmente, Murray (1999) vislumbrou algumas práticas que poderiam ser adotadas pela função de compras, a fim de contribuir estrategicamente para a consecução dos objetivos governamentais, tais como: i) desenvolvimento econômico local, usando brechas da legislação dos contratos públicos para melhorar a competitividade das empresas locais e reduzir os custos; ii) indução de melhorias ambientais, optando por produtos ecológicos ou considerando os sistemas de gestão ambiental dos fornecedores para sua habilitação; iii) preferência por fornecedores que já tenham prestado serviços anteriormente; iv) aproveitamento de oportunidades existentes 
durante o desenvolvimento de uma nova legislação; v) melhoria da qualidade no fornecimento, tanto propiciando o desenvolvimento de fornecedores quanto buscando a mais alta qualidade ao melhor preço; e vi) promoção do perfil da organização junto a atores externos.

Posteriormente, Johnson et al. (2003) ratificaram que existem diferenças significativas entre as funções de compras dos setores público e privado. Em um dos eixos estudados pelos autores, os resultados indicaram que há um menor nível geral de envolvimento da função de compras do setor público em grandes atividades organizacionais em comparação com as organizações privadas, motivo pelo qual os autores sugerem haver oportunidades para envolver a função de compras na estratégia organizacional, sobretudo no âmbito do setor público.

Matthews (2005), por seu turno, constatou que as contratações públicas estão se concentrando mais no planejamento de ponta e menos nos procedimentos rotineiros ou táticos, listando algumas tarefas específicas relacionadas com a evolução da função de compras para uma natureza estratégica, de vanguarda, tais como: i) alianças com fornecedores; ii) planejamento e controle do orçamento; iii) terceirização (global) do mercado de bens e serviços; iv) análise de custo do ciclo de vida; v) planejamento das aquisições; e vi) gestão dos gastos para contratar ou fornecer produtos e serviços.

A revisão de literatura de Zheng et al. (2007) confirmou que as organizações do setor público reconhecem cada vez mais o papel estratégico que os contratos públicos podem desempenhar, não apenas em reduzir custos, mas também na consecução de objetivos governamentais mais amplos.

Adicionalmente, na percepção de Arlbjørn e Freytag (2012), o setor público também faz parte de uma cadeia com fornecedores e clientes, sendo que, de fato, o escopo das organizações públicas é muito mais amplo que o das empresas privadas, em termos de diversidade e necessidades dos clientes atendidos, o que tem conduzido a um crescente reconhecimento do papel estratégico das contratações públicas.

Enfim, Patrucco et al. (2017) investigaram o status da função de compras no setor público, no sentido de descrever até que ponto as compras podem ser uma função que agrega valor, e demonstraram que existe não só uma correlação direta entre o status da função (ex:. alta posição e autoridade na hierarquia de uma organização) e sua maturidade estratégica (ex: estratégia clara, formal e explicitamente definida), como também a necessidade de alinhamento entre as decisões da função de compras e as estratégias dos outros departamentos.

Realizado o esboço teórico atinente ao tema ora pesquisado, parte-se para a descrição dos métodos e técnicas adotados para alcançar os objetivos do presente trabalho.

\section{Método}

Para atingir o objetivo proposto nesta pesquisa, optou-se por conduzir um estudo teórico-empírico, conforme os critérios descritos nas próximas seções. Quanto à sua classificação, trata-se de uma pesquisa aplicada, de natureza qualitativa, com objetivos descritivos e adotando procedimentos técnicos de uma revisão da literatura.

Este tipo de estudo ajuda a estabelecer uma visão clara de fontes de informação, preocupações teóricas e abordagens de pesquisa, possibilitando verificar se há ou não consistência entre as várias atividades de pesquisa dentro da área estudada (BURGESS; SINGH; KOROGLU, 2006).

Cabe ressaltar que, conforme Cronin, Ryan e Coughlan (2008), existem dois tipos de revisão da literatura, a narrativa e a sistemática. A narrativa não deixa claro os critérios utilizados para busca e seleção dos artigos, enquanto que, na sistemática, esses critérios são claros e explícitos para garantir a replicabilidade do estudo. Neste artigo, foi utilizado o protocolo proposto por Cronin, Ryan e Coughlan (2008), cujas etapas estão descritas a seguir.

1) Definição da questão de pesquisa: qual é o estado da arte nas publicações nacionais sobre o tema de compras públicas estratégicas?

2) Definição do conjunto de critérios de inclusão e exclusão: os critérios abrangem as bases científicas selecionadas, período de publicação, tipos de artigos, palavras-chave e operadores booleanos. Optou-se pelas bases Scielo, Spell e Periódicos Capes, cuja publicação tenha ocorrido a partir do ano 2000 até julho de 2017 (mês em que foi efetivada a pesquisa). Considerando que não foram obtidos muitos resultados, optou-se por utilizar, também, a base do Google Acadêmico, considerando o mesmo período de publicação. As palavras-chave consideradas foram "Compras públicas AND Compras estratégicas"; "Compras públicas AND Estratégia" e "Compras públicas". No tocante ao tipo de artigo, definiu-se que seriam abrangidos somente artigos completos publicados em periódicos, o que excluiu aqueles publicados em anais de eventos - considerados trabalhos em construção -, bem como patentes e capítulos de livros. Ademais, convencionou-se que seriam analisados somente trabalhos publicados em periódicos com estratos de avaliação no sistema Qualis Capes iguais ou superiores a B2, 
em qualquer idioma. No que se refere aos operadores booleanos utilizados, optou-se pelo operador AND, excluindo-se os operadores NOT e OR.

3) Seleção e acesso da literatura: a localização dos artigos ocorreu por meio da busca em cada uma das bases supracitadas. Na base Scielo, com os termos "Compras públicas AND Compras estratégicas", não foi encontrado nenhum resultado. Realizou-se nova busca com os termos "Compras públicas AND Estratégia", obtendo-se 7 artigos. Na base Spell, utilizando-se os critérios acima explicitados, não foi encontrado nenhum resultado. Assim, excluiu-se o termo "AND Compras estratégicas" e manteve-se apenas "Compras Públicas", tendo sido identificados 12 artigos. Na base Periódicos Capes, com os termos "Compras públicas AND Compras estratégicas", obteve-se 32 artigos. Por fim, no Google Acadêmico, obteve-se 15.200 resultados. Até a página 31 do buscador foram encontrados resultados mais aderentes. No entanto, os resultados ficaram escassos à medida que se foi avançando na busca, sendo que a partir da página 32 e até a página 40 não foram mais encontrados resultados aderentes nos títulos. Desta forma, optou-se por encerrar a busca nessa base, com 42 artigos aderentes aos critérios de busca.

4) Avaliação da qualidade da literatura incluída na revisão: inicialmente, nenhum dos resultados da base Periódicos Capes, após leitura dos títulos e resumos, mostrou-se aderente à pesquisa, portanto os 32 artigos foram eliminados. Restaram, assim, 61 artigos $(7+12+42)$ das outras três bases (Scielo, Spell e Google Acadêmico, respectivamente). Desses, 8 artigos foram eliminados por estarem duplicados, sobrando 53 artigos distintos. Enfim, foram eliminados 38 artigos que não atendiam ao critério de serem iguais ou superiores ao extrato B2 do sistema Qualis Capes, restando os 15 artigos que compuseram este trabalho, os quais foram analisados na íntegra.

5) Análise, síntese e disseminação dos resultados:nesta fase ocorreu a avaliação detalhada de cada um dos 15 artigos considerados, a fim de possibilitar uma análise bibliométrica. Visando a propiciar uma análise holística sobre a pesquisa do campo, foram levantados os indicadores das seguintes categorias: 1) nome do periódico; 2) ano de publicação; 3) quantidade de autores; 4) vinculação acadêmica dos autores dos estudos; 5) assunto dos estudos; e 6) enquadramento dos estudos. Os artigos identificados como teórico-empíricos foram analisados, ainda, quanto aos seguintes critérios: 7) natureza/abordagem do estudo; 8) setor da economia pesquisado; 9) instrumentos de coleta de dados utilizados pelos pesquisadores; e 10) técnicas de análises de dados empregadas. Ademais, a análise completa dos artigos possibilitou sua discussão e também a identificação de lacunas na literatura, as quais podem ser desenvolvidas em estudos ulteriores. O Quadro 1 apresenta os artigos abrangidos pela revisão sistemática da literatura.

Quadro 1: Artigos Selecionados.

\begin{tabular}{|c|c|c|c|c|}
\hline $\mathbf{N}$ & Autor(es) & Título & Periódico & $\begin{array}{c}\text { Ano da } \\
\text { publicação }\end{array}$ \\
\hline 1 & PIMENTA, Carlos César & $\begin{array}{l}\text { Gestión de compras y contrataciones } \\
\text { gubernamentales }\end{array}$ & RAE eletrônica & $(2002)$ \\
\hline 2 & CARDOSO, Renê Fernando & $\begin{array}{l}\text { Um estudo sobre os resultados da utilização da } \\
\text { Bolsa Eletrônica de Compras no Governo do } \\
\text { Estado de São Paulo }\end{array}$ & $\begin{array}{l}\text { Revista do } \\
\text { Serviço Público }\end{array}$ & (2014) \\
\hline 3 & $\begin{array}{l}\text { MENEZES, Ronald do Amaral; } \\
\text { SILVA, Renaud Barbosa da; } \\
\text { LINHARES, Alexandre }\end{array}$ & $\begin{array}{l}\text { Leilões eletrônicos reversos multiatributo: } \\
\text { uma abordagem de decisão multicritério } \\
\text { aplicada às compras públicas brasileiras }\end{array}$ & \begin{tabular}{l|} 
Revista de \\
Administração \\
Contemporânea \\
\end{tabular} & (2007) \\
\hline 4 & $\begin{array}{l}\text { FARIA, Evandro Rodrigues de; } \\
\text { FERREIRA, Marco Aurélio } \\
\text { Marques; SANTOS, Lucas Maia } \\
\text { dos; SILVEIRA, Suely de Fátima } \\
\text { Ramos }\end{array}$ & $\begin{array}{l}\text { Fatores determinantes na variação dos preços } \\
\text { dos produtos contratados por pregão eletrônico }\end{array}$ & $\begin{array}{l}\text { Revista de } \\
\text { Administração } \\
\text { Pública }\end{array}$ & (2010) \\
\hline 5 & $\begin{array}{lrr}\text { SOARES, } & \text { Laura } & \text { Letsch; } \\
\text { VICENTE, } & \text { Ernesto } & \text { Fernando } \\
\text { Rodrigues } & & \\
\end{array}$ & $\begin{array}{l}\text { Divulgação das compras públicas de alimentos } \\
\text { para a merenda escolar em municípios } \\
\text { catarinenses }\end{array}$ & $\begin{array}{l}\text { Gestão \& } \& \\
\text { Regionalidade }\end{array}$ & (2011) \\
\hline 6 & $\begin{array}{lr}\text { TRIDAPALLI, Juarez } & \text { Paulo; } \\
\text { FERNANDES, } & \text { Elton; } \\
\text { MACHADO, Waltair Vieira } \\
\end{array}$ & $\begin{array}{l}\text { Gestão da cadeia de suprimento do setor } \\
\text { público: uma alternativa para controle de } \\
\text { gastos correntes no Brasil }\end{array}$ & $\begin{array}{l}\text { Revista de } \\
\text { Administração } \\
\text { Pública }\end{array}$ & (2011) \\
\hline 7 & $\begin{array}{l}\text { SILVA, Renato Cader da; } \\
\text { BARKI, Teresa Villac Pinheiro }\end{array}$ & $\begin{array}{l}\text { Compras públicas compartilhadas: a prática } \\
\text { das licitações sustentáveis }\end{array}$ & \begin{tabular}{|l|} 
Revista do \\
Serviço Público \\
\end{tabular} & (2012) \\
\hline 8 & $\begin{array}{l}\text { MOREIRA, Marina Figueiredo; } \\
\text { VARGAS, Eduardo Raupp de }\end{array}$ & $\begin{array}{l}\text { Quando o governo é o mercado: compras } \\
\text { governamentais e inovação em serviços de } \\
\text { software }\end{array}$ & $\begin{array}{lr}\text { Revista } & \text { de } \\
\text { Administração } & \mathrm{e} \\
\text { Inovação } & \end{array}$ & (2012) \\
\hline
\end{tabular}




\begin{tabular}{|c|c|c|c|c|}
\hline 9 & \begin{tabular}{|l|r|} 
FREITAS, Marcelo de; \\
MALDONADO, José Manuel \\
Santos de Varge
\end{tabular} & $\begin{array}{l}\text { O pregão eletrônico e as contratações de } \\
\text { serviços contínuos }\end{array}$ & $\begin{array}{l}\text { Revista de } \\
\text { Administração } \\
\text { Pública }\end{array}$ & (2013) \\
\hline 10 & \begin{tabular}{|l|} 
CALDAS, Eduardo de Lima; \\
NONATO, Raquel Sobral
\end{tabular} & \begin{tabular}{|llll}
$\begin{array}{l}\text { Compras públicas } \\
\text { desenvolvimento local }\end{array}$ & promoção do \\
\end{tabular} & $\begin{array}{l}\text { Revista do } \\
\text { Serviço Público }\end{array}$ & (2013) \\
\hline 11 & $\begin{array}{l}\text { TEIXEIRA, Maria Gracinda } \\
\text { Carvalho; AZEVEDO, Luís Peres }\end{array}$ & $\begin{array}{l}\text { A agenda ambiental pública: barreiras para a } \\
\text { articulação entre critérios de sustentabilidade e } \\
\text { as novas diretrizes na Administração Pública } \\
\text { Federal brasileira }\end{array}$ & $\begin{array}{l}\text { Revista } \\
\text { Eletrônica de } \\
\text { Administração }\end{array}$ & (2013) \\
\hline 12 & $\begin{array}{l}\text { FREITAS, Rony Klay Viana de; } \\
\text { DACORSO, Antonio Luiz Rocha }\end{array}$ & $\begin{array}{l}\text { Inovação aberta na gestão pública: análise do } \\
\text { plano de ação brasileiro para a Open } \\
\text { Government Partnership }\end{array}$ & $\begin{array}{l}\text { Revista de } \\
\text { Administração } \\
\text { Pública }\end{array}$ & (2014) \\
\hline 13 & $\begin{array}{l}\text { CABRAL, Sandro; REIS, Paulo } \\
\text { Ricardo da Costa; SAMPAIO, } \\
\text { Adilson da Hora }\end{array}$ & $\begin{array}{l}\text { Determinantes da participação e sucesso das } \\
\text { micro e pequenas empresas em compras } \\
\text { públicas: uma análise empírica }\end{array}$ & $\begin{array}{l}\text { Revista de } \\
\text { Administração } \\
\text { (São Paulo) }\end{array}$ & $(2015)$ \\
\hline 14 & \begin{tabular}{|l|} 
OLIVEIRA, Bernardo Carlos \\
Spaulonci Chiachia Matos de; \\
SANTOS, Luis Miguel Luzio dos \\
\end{tabular} & $\begin{array}{l}\text { Compras públicas como política para o } \\
\text { desenvolvimento sustentável }\end{array}$ & $\begin{array}{l}\text { Revista de } \\
\text { Administração } \\
\text { Pública }\end{array}$ & $(2015)$ \\
\hline 15 & \begin{tabular}{|l|} 
COUTO, Hugo Leonnardo \\
Gomides do; RIBEIRO, Francis \\
Lee
\end{tabular} & $\begin{array}{l}\text { Objetivos e desafios da política de compras } \\
\text { públicas sustentáveis no Brasil: a opinião dos } \\
\text { especialistas }\end{array}$ & $\begin{array}{l}\text { Revista de } \\
\text { Administração } \\
\text { Pública }\end{array}$ & (2016) \\
\hline
\end{tabular}

Na apresentação dos resultados, os artigos serão mencionados por seu número de referência, correspondente ao número sequencial "N" apresentado no Quadro 1.

\section{Resultados}

A exemplo de Burgess, Singh e Koroglu (2006), considera-se que a amplitude das perspectivas cobertas pelas dez dimensões ora detalhadas é adequada para desenvolver uma sólida compreensão acerca da literatura sobre compras públicas estratégicas, abordando preocupações conceituais e metodológicas de pesquisa e permitindo verificar se há e quais são as ligações e a consistência entre as várias atividades de pesquisa no campo.

Os periódicos que mais publicaram foram a Revista de Administração Pública, uma publicação da Escola Brasileira de Administração Pública e de Empresas da Fundação Getulio Vargas (FGV), com um total de 6 artigos ([4], [6], [9], [12], [14] e [15]), e a Revista do Serviço Público, editada pela Escola Nacional de Administração Pública, com 3 artigos ([2], [7] e [10]). Cada um dos demais artigos foram publicados em periódicos distintos, quais sejam: Gestão \& Regionalidade ([5]), Revista de Administração de Empresas ([1]), Revista de Administração da Universidade de São Paulo ([13]), Revista de Administração Contemporânea ([3]), Revista de Administração e Inovação ([8]) e Revista Eletrônica de Administração ([11]). A Figura 1 sumariza estes resultados.

Figura 1: Distribuição dos artigos de acordo com o periódico.

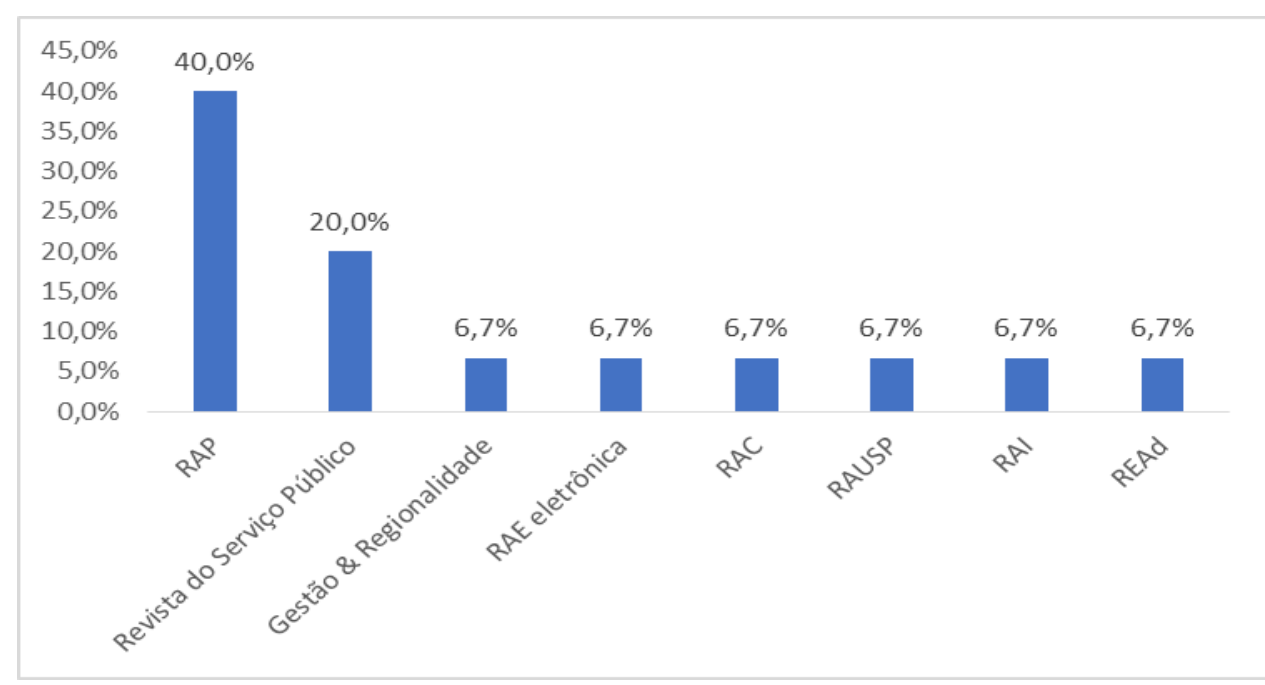

A distribuição dos artigos de acordo com o ano da sua publicação é a seguinte: 1 em 2002 ([1]), 1 em 2004 ([2]), $1 \mathrm{em} 2007$ ([3]), $1 \mathrm{em} 2010$ ([4]), $2 \mathrm{em} 2011$ ([5] e [6]), $2 \mathrm{em} 2012$ ([7] e [8]), $3 \mathrm{em} 2013$ ([9], [10] e [11]), $1 \mathrm{em}$ 2014 ([12]), 2 em 2015 ([13] e [14]) e 1 em 2016 ([15]), conforme representado na Figura 2. 
Figura 2: Distribuição dos artigos de acordo com o ano da sua publicação.

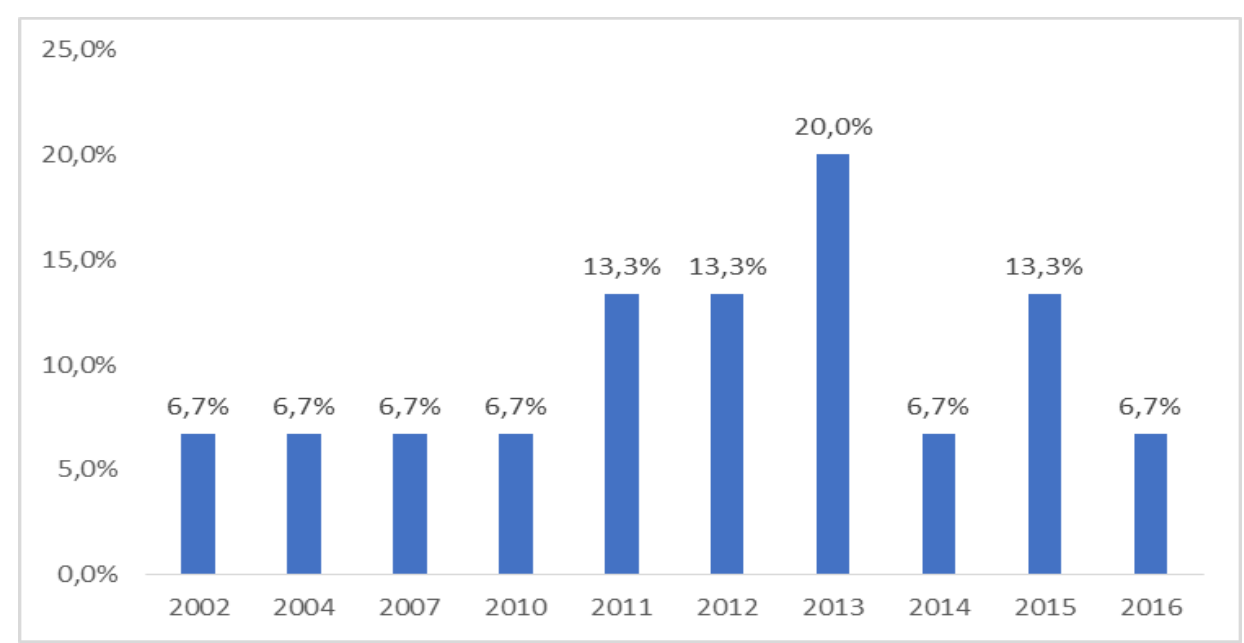

Quanto ao número de autores, 9 artigos foram desenvolvidos por uma dupla de pesquisadores ([5], [7], [8], [9], [10], [11], [12], [14] e [15]). Quanto aos demais, 2 artigos são assinados por apenas um autor ([1] e [2]), 3 artigos são assinados por três autores ([3], [6] e [13]) e 1 artigo é assinado por quatro autores ([4]). A Figura 3 representa essa distribuição.

Figura 3: Distribuição dos artigos de acordo com o número de autores.

\begin{tabular}{|c|c|c|c|c|}
\hline \multicolumn{5}{|l|}{$70,0 \%$} \\
\hline $60,0 \%$ & & $60,0 \%$ & & \\
\hline $50,0 \%$ & & & & \\
\hline $40,0 \%$ & & & & \\
\hline $30,0 \%$ & & & & \\
\hline $20,0 \%$ & $13,3 \%$ & & & \\
\hline $10,0 \%$ & & & & $6,7 \%$ \\
\hline & 1 & 2 & 3 & 4 \\
\hline
\end{tabular}

Acerca da vinculação acadêmica dos autores, identificou-se 22 diferentes instituições à época da publicação, sendo as mais mencionadas, cada uma com dois artigos: Escola de Administração de Empresas de São Paulo da FGV ([1] e [10]), Universidade de São Paulo ([7] e [10]) e Universidade Estadual de Londrina ([6] e [14]).

As demais instituições, cada uma relacionada a uma publicação, são: Escola Brasileira de Administração Pública e de Empresas da FGV ([3]), Escola Nacional de Saúde Pública da Fiocruz ([9]), Faculdades Integradas Torricelli ([2]), Pontifícia Universidade Católica de São Paulo ([14]), Universidade de Brasília ([8]), Universidade Estadual de Campinas ([7]), Universidade Federal da Bahia ([13]), Universidade Federal de Goiás ([15]), Universidade Federal de Minas Gerais ([11]), Universidade Federal de Santa Catarina ([5]), Universidade Federal de Sergipe ([12]), Universidade Federal de Viçosa ([4]), Universidade Federal do Amazonas ([6]), Universidade Federal do Rio de Janeiro ([6]), Universidade Federal Rural do Rio de Janeiro ([11]) e Universidade Paulista ([2]), como apresentado na Figura 4. 
Figura 4: Distribuição dos artigos de acordo com a vinculação acadêmica.

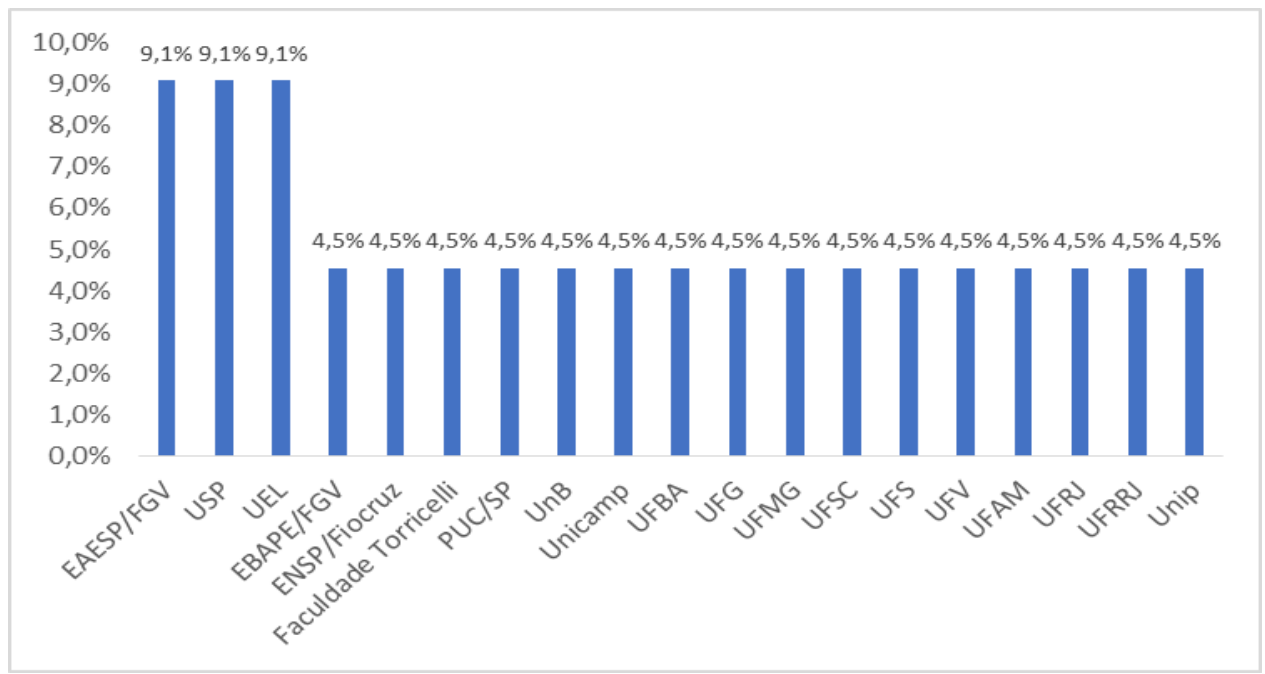

Relativamente ao assunto estudado, 5 artigos abordaram principalmente a questão da "sustentabilidade ambiental, social e/ou econômica" ([10], [11], [13], [14] e [15]), representando a categoria temática mais relevante. Na sequência, com 3 artigos cada, os assuntos eleitos foram "contratação eletrônica" ([2], [5] e [6]) e "seleção de fornecedores" ([3], [4] e [9]). Por fim, a "indução à inovação" foi o assunto estudado em 2 artigos ([8] e [12]), enquanto que a "parceria interorganizacional" (compras compartilhadas) ([7]) e o "potencial da função de compras" ([1]) foi tema de 1 artigo cada, como sumarizado na Figura 5.

Figura 5: Distribuição dos artigos de acordo com o assunto estudado.

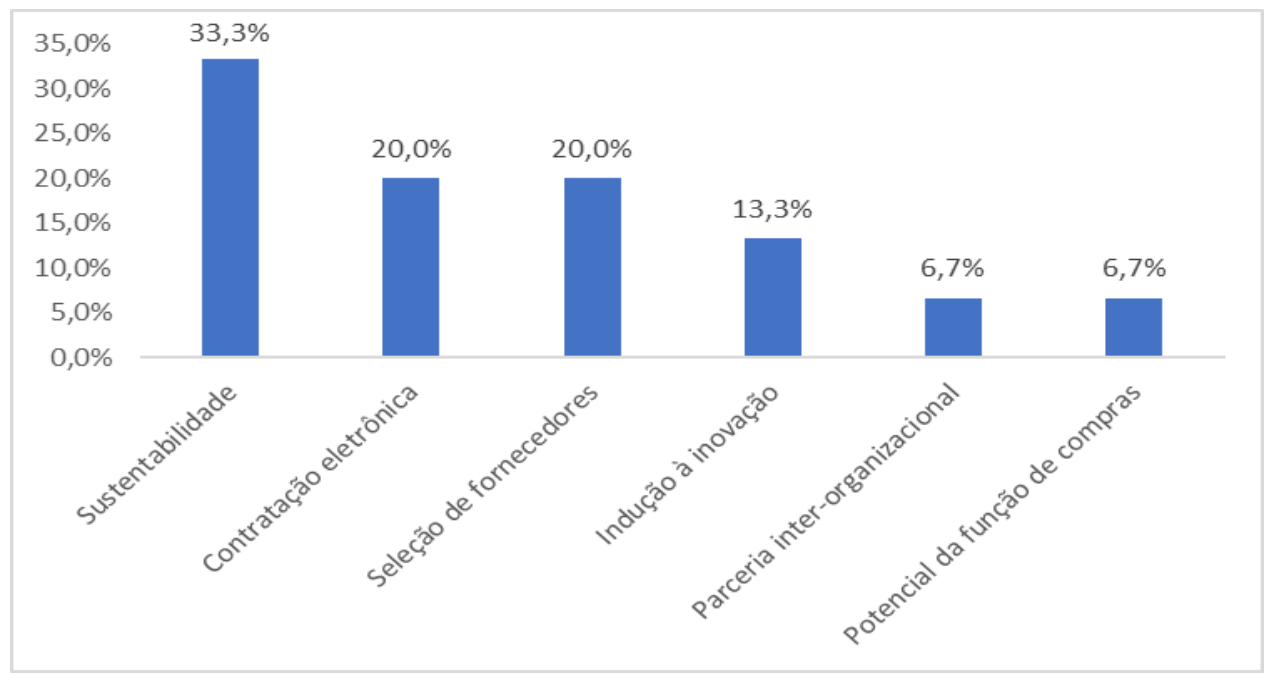

No tocante ao enquadramento dos estudos, foi utilizada a definição de Machado-da-Silva, Cunha e Amboni (1990), segundo os quais a pesquisa é teórico-empírica quando o estudo apresenta dados coletados, que são analisados e confrontados com correntes teóricas revisadas, ao passo que a pesquisa é teórica quando os trabalhos, por não apresentarem dados empíricos, limitam-se à articulação, formulação e contraposição de conceitos teóricos.

De acordo com tal classificação, 14 artigos enquadraram-se como teórico-empíricos ([2], [3], [4], [5], [6], [7], [8], [9], [10], [11], [12], [13], [14] e [15]) e apenas 1 como pesquisa teórica ([1]), como se vê na Figura 6. 
Figura 6: Distribuição dos artigos de acordo com o enquadramento da pesquisa.

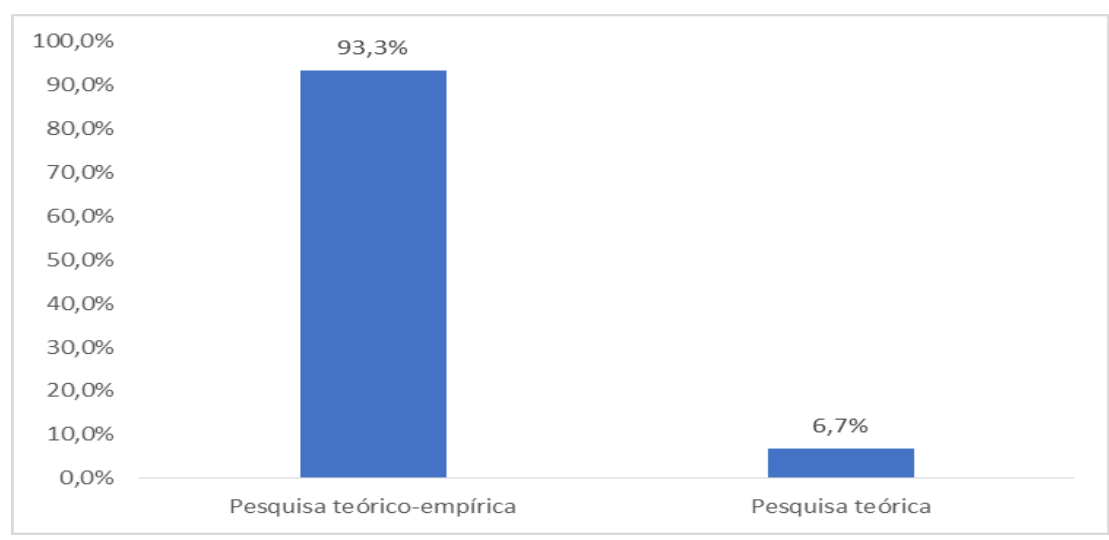

Passa-se a analisar, agora, apenas os 14 estudos teórico-empíricos. Dentre esses, 10 artigos utilizaram uma abordagem qualitativa ([2], [5], [6], [7], [8], [9], [10], [11], [12] e [14]), 2 usaram uma abordagem quantitativa ([3] e [13]) e 2 empregaram uma abordagem multimétodo ([4] e [15]), como mostra a Figura 7.

Figura 7: Distribuição dos artigos de acordo com a natureza/abordagem.

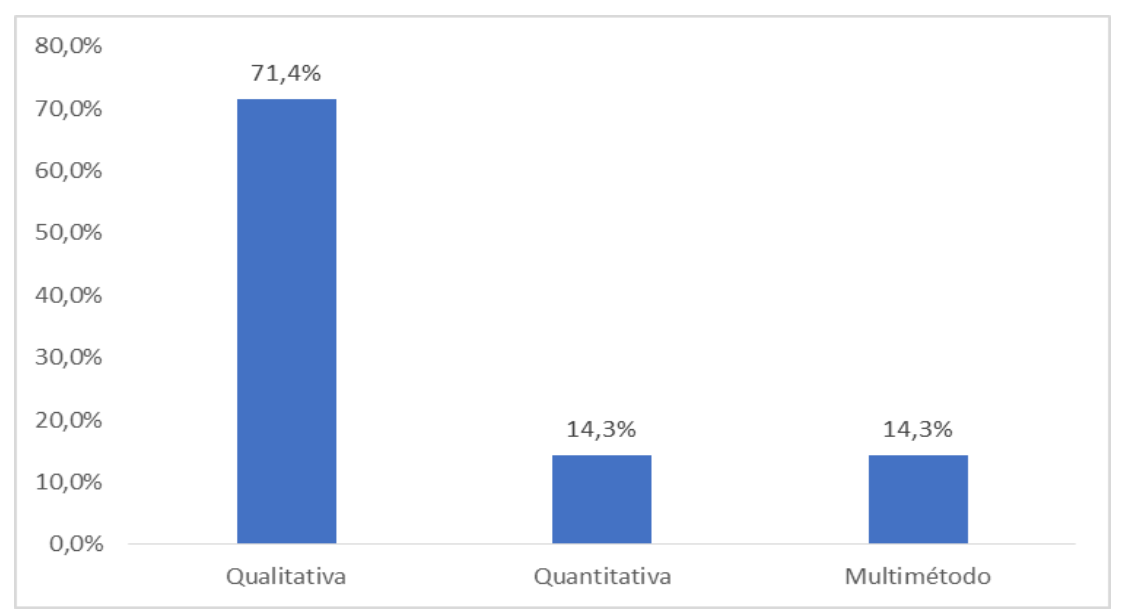

No que diz respeito ao setor da economia, optou-se por utilizar a definição de Fernandes (1994), para quem o primeiro setor é caracterizado pelas organizações públicas de interesse e/ou finalidade pública, o segundo setor contém as organizações privadas de interesse e/ou finalidade privada e, por fim, o terceiro setor é composto das organizações privadas de interesse e/ou finalidade pública.

Com base em tal definição, 11 artigos focaram-se no primeiro setor ([2], [4], [5], [6], [7], [9], [10], [11], [12], [13] e [14]), 2 artigos enfatizaram o primeiro e o segundo setores ([3] e [15]) e 1 artigo concentrou-se no segundo setor ([8]), conforme é visto na Figura 8.

Figura 8 - Distribuição dos artigos de acordo com o setor da economia

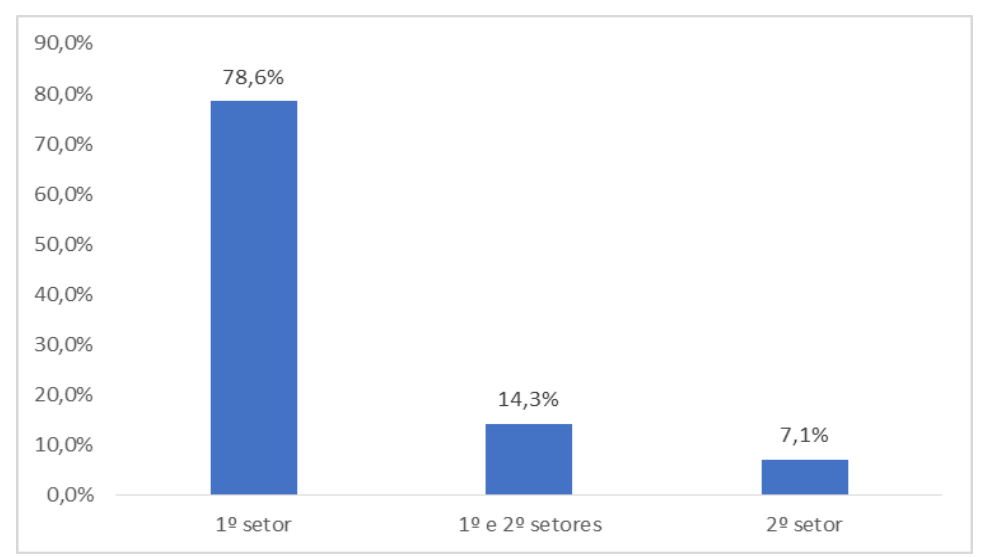

Nos artigos pesquisados, foram utilizados diversos instrumentos de coleta de dados: análise de bases de dados em 
5 artigos ([4], [5], [9], [13] e [14]), documentos em 5 artigos ([6], [7], [11], [12] e [14]), entrevistas em 4 artigos ([6], [8], [10] e [11]), experimento/simulação em 1 artigo ([3]), observação em 2 artigos ([7] e [10]) e questionário em 4 artigos ([2], [4], [6] e [15]), como se verifica na Figura 9.

Figura 9: Distribuição dos artigos de acordo com o instrumento de coleta.

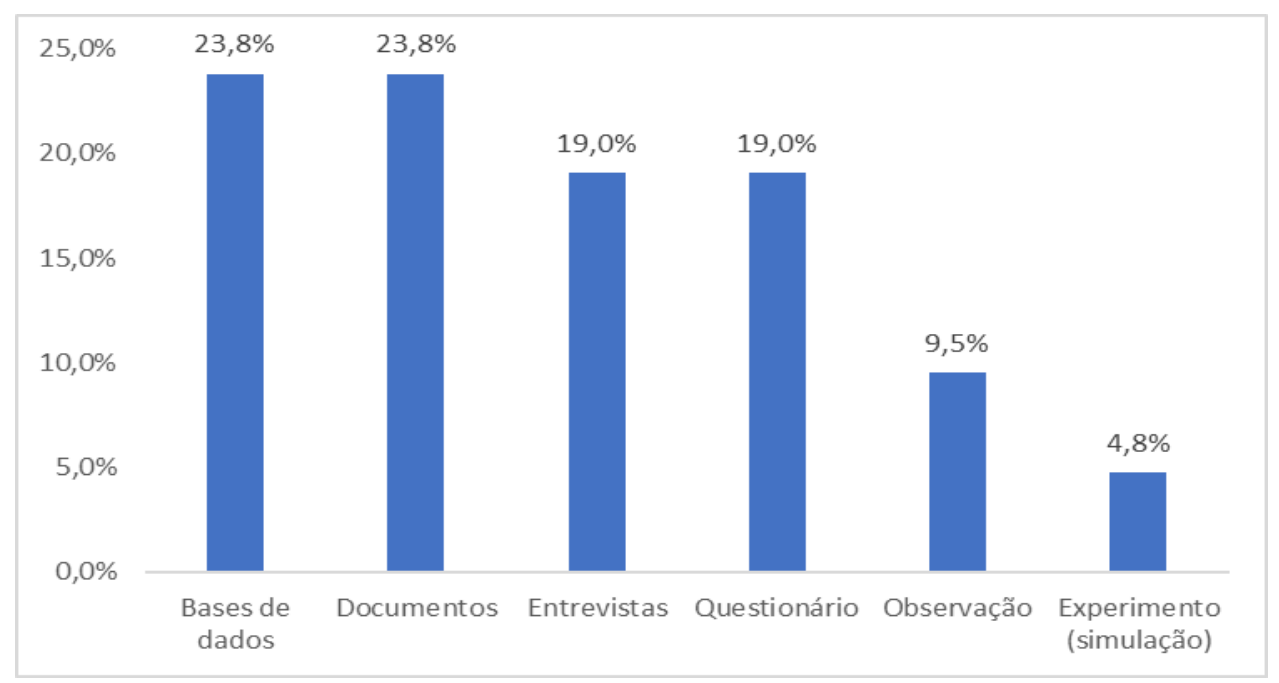

Enfim, quanto à análise de dados, a técnica preponderante foi a análise de conteúdo em documentos, empregada em 6 artigos ([5], [6], [9], [11], [12] e [14]). Na sequência, as técnicas mais adotadas foram a análise de conteúdo de entrevistas em 3 artigos ([2], [8] e [15]) e a análise da evidência produzida pelos pesquisadores - em estudos de casos - em 2 artigos ([7] e [10]). Por último, as seguintes técnicas foram utilizadas em 1 artigo cada: análise da decisão ([3]), análise de correlação ([4]), análise do discurso ([11]), regressão linear múltipla ([4]), regressão logística probit ([13]) e técnica Delphi - nível de consenso ([15]), como sumarizado na Figura 10.

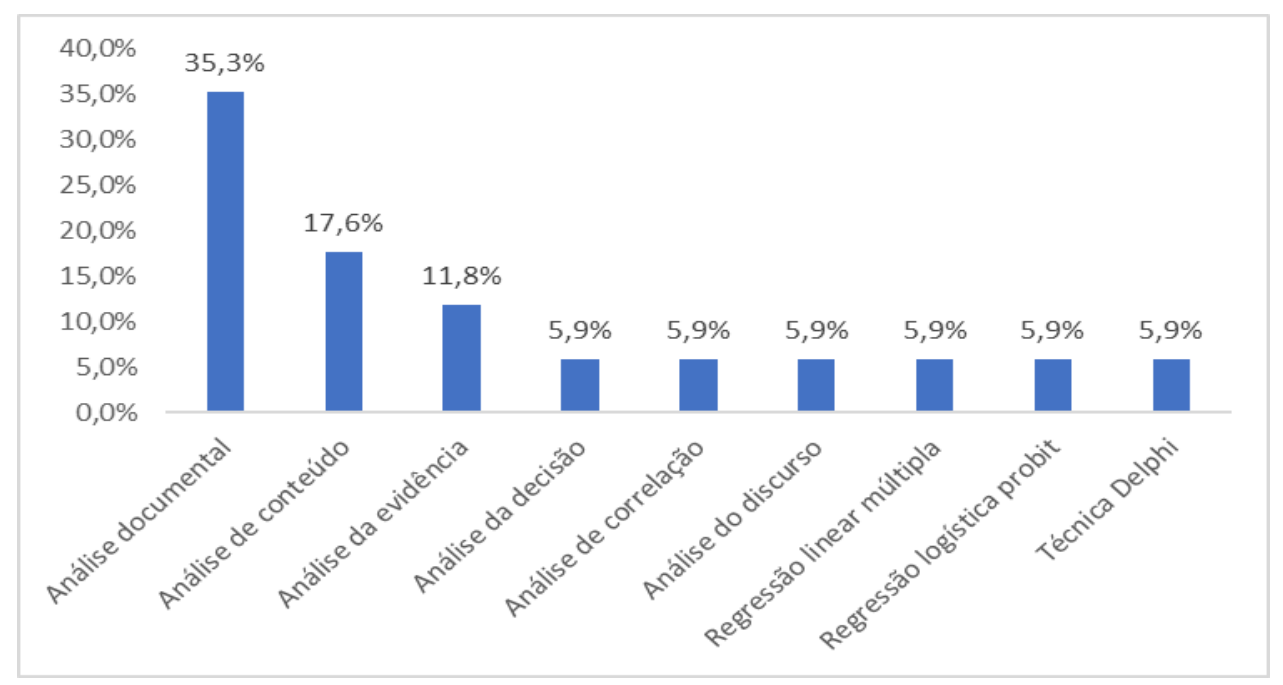

Figura 10 - Distribuição dos artigos de acordo com a técnica de análise

\section{Discussão e Agenda de Pesquisa}

Com base nas informações obtidas com essa pesquisa, pode-se traçar um panorama acerca da evolução dos estudos concernentes a compras públicas estratégicas no país.

Houve uma elevação da produção no período entre 2011 e 2015, sendo que o ápice foi atingido em 2013, com 20\% das publicações. Possivelmente devido ao fato de que, em 2013, o principal marco regulatório das compras públicas no Brasil, qual seja, a Lei $n^{\circ} 8.666 / 1993$, completou 20 anos, e, diante disso, o interesse pelo tema foi reativado, impulsionando as pesquisas acerca do tema, conforme apontado por Fiuza e Medeiros (2014).

Em relação aos autores dos artigos, chama atenção o fato de que, na amostra pesquisada, houve um total de 33 pesquisadores (média de 2,2 por artigo), sendo que, curiosamente, são todos diferentes entre si. Ou seja, nenhum 
autor assinou mais do que um artigo, não sendo possível, assim, identificar um pesquisador que tenha publicado mais sobre o tema. Tendo em vista se tratar de um assunto ainda incipiente na literatura, pode ser que não tenha transcorrido tempo suficiente para que um autor se destaque no campo de estudos da temática.

No tocante aos atributos metodológicos, os resultados desta pesquisa indicam um padrão na literatura revisada com prevalência da abordagem qualitativa ( $71,4 \%)$, utilizando bases de dados $(23,8 \%)$, outros tipos de documentos $(23,8 \%)$, entrevistas $(19 \%)$ e questionários $(19 \%)$ como instrumentos de coleta de dados e aplicando as técnicas de análise de conteúdo documental $(35,3 \%)$, análise de conteúdo de entrevistas $(17,6 \%)$ e análise da evidência $(11,8 \%)$ para a análise dos dados.

Ocorre que, de acordo com a literatura acadêmica, têm sido reconhecidas a importância e as vantagens de diversificar os métodos de pesquisas (incluindo as abordagens, os instrumentos de coleta e as técnicas de análise) para estudar problemas de pesquisa em ciências sociais e cobrir de forma holística determinado campo de estudo, fenômeno conhecido por triangulação, que provê mais validade e confiabilidade às pesquisas qualitativas (FLICK, 2009).

Por exemplo, para Creswell, Clark, Gutmann e Hanson (2003), uma vez que os fenômenos sociais mostram-se bastante complexos, são necessários diferentes tipos de métodos para entender melhor essas complexidades. Em reforço, Gomes e Araújo (2005) destacam que o campo das ciências sociais é rico na utilização de métodos variados de investigação. Tendo em vista que o objeto de estudo da administração é de difícil compreensão, o emprego de métodos que englobem os mais variados aspectos e que proporcionem conhecimento aprofundado sobre as diversas questões organizacionais permite ao pesquisador observar os diversos aspectos relacionados a determinado objeto de estudo.

Assim, tais resultados podem ser interpretados como um convite à produção de mais pesquisas privilegiando distintas abordagens metodológicas, como quantitativa ou multimétodos, que, juntas, representaram apenas $28,6 \%$ da amostra. Outrossim, pesquisas multimétodos, as quais mesclam abordagens qualitativa e quantitativa, possibilitam a propalada triangulação metodológica, permitindo uma melhor compreensão do fenômeno, ao mesmo tempo em que esforços para compreendê-lo ou mensurá-lo são engendrados.

Também há espaço para a utilização de outros instrumentos de coleta de dados, considerando que a observação foi utilizada em apenas $9,5 \%$ da amostra e o experimento, em $4,8 \%$. Outros instrumentos, como, por exemplo, o grupo focal, sequer foram empregados. O mesmo aplica-se às técnicas de análise de dados, que podem e devem ser diversificadas.

Interessante registrar que, nos 4 artigos que utilizaram questionário, não foi realizado um processo de desenvolvimento e validação do instrumento de coleta de dados. A construção e a validação de uma escala, baseada na psicometria, são procedimentos cada vez mais utilizados para operacionalizar a variável pesquisada. Conforme ressaltado por Demo (2008), em trabalho sobre gestão de pessoas, a construção da escala tem por base, além de itens criados a partir da literatura e instrumentos previamente validados, a análise semântica e a análise de juízes (consistência, concordância/consenso e pertinência dos itens). Por sua vez, a validação psicométrica da escala remete-se à coleta, limpeza e tratamento dos dados, à análise fatorial e à aferição da confiabilidade dos fatores por meio do alfa de Cronbach $(\alpha)$. Assim, conforme a autora, somente a partir da adoção desses procedimentos seria possível afirmar que a escala, o instrumento ou o questionário desenvolvido possuem validade para efetivamente medir aquilo a que se propõem.

Se, por um lado, tal resultado pode indicar uma tendência no campo pesquisado (no sentido de eventualmente ser dispensável a utilização de uma escala validada), por outro lado não se pode ignorar que isso ilustra uma importante lacuna na literatura a ser aproveitada para o progresso do campo. Destaca-se, ainda, a ausência de estudos no terceiro setor, o qual possui especificidades que merecem atenção dos pesquisadores do tema.

Percebe-se, assim, que os resultados da pesquisa demonstraram que a função de compras torna-se mais estratégica numa organização pública quando cultiva competências relacionadas, em especial, ao desenvolvimento sustentável em seu tripé ambiental, social e econômico $(33,3 \%)$, e ainda, com menos ênfase nos artigos revisados, ao uso otimizado de contratação eletrônica $(20 \%)$, aos critérios de seleção dos fornecedores $(20 \%)$, à indução da inovação $(13,3 \%)$ e à parceria interorganizacional $(6,7 \%)$.

Tal constatação vai ao encontro não só do que foi disposto pelos autores mencionados no referencial teórico, como também de artigos internacionais que prescreveram as supracitadas competências, quais sejam:

- Sustentabilidade ambiental, social e/ou econômica: desenvolvimento de critérios sustentáveis para as compras (BRATT et al., 2013); compras com inclusividade aumentada e desenvolvimento sustentável (LENFERINK; TILLEMA; ARTS, 2013); distinção entre objetivos ambientalmente amigáveis e 
socialmente responsáveis (AMANN et al., 2014); equilíbrio das demandas e avaliação do custo do ciclo de vida total (SMITH et al., 2016).

- Contratação eletrônica: estratégias de contratação eletrônica e estratégia organizacional (WALKER; HARLAND, 2008); expectativas de transformação associadas à contratação eletrônica (MCCUE; ROMAN, 2012).

- Seleção de fornecedores: intervenções estratégicas em mercados escassos (JOHNSTON; GIRTH, 2012); métodos de seleção de fornecedores e processo competitivo (BERGMAN; LUNDBERG, 2013).

- Indução à inovação: formas que a contratação pública pode assumir como estratégia na política de inovação (EDLER; GEORGHIOU, 2007); contratações públicas e os efeitos no sucesso da inovação (ASCHHOFF; SOFKA, 2009); promoção de práticas favoráveis à inovação nas diferentes naturezas de bens e serviços adquiridos (UYARRA; FLANAGAN, 2010).

- Parceria interorganizacional: grupos de compras entre organizações (NOLLET; BEAULIEU, 2005); compras com serviço compartilhado entre organizações (MURRAY; RENTELL; GEERE, 2008).

À guisa de lacuna, ante o pequeno número de artigos encontrados nesta revisão sistemática, primeiramente devese proceder com a realização de mais pesquisas sobre essas competências a fim de ratificar se elas estão realmente relacionadas a uma vertente estratégica da função de compras nas organizações públicas. Além disso, outras competências identificadas na literatura estrangeira como possivelmente relacionadas ao potencial estratégico da função de compras no setor público ainda não foram pesquisadas por autores brasileiros, como, por exemplo, adoção de práticas relacionadas à mentalidade enxuta (WATERMAN; MCCUE, 2012).

\section{Conclusões}

O presente trabalho pretendeu contribuir para a produção acadêmica a respeito das compras estratégicas no setor público ao informar a prática da pesquisa sobre o assunto no Brasil e oferecer uma agenda de pesquisa a partir das lacunas identificadas na literatura.

Apesar disso, vale ressaltar que este estudo não almeja esgotar a literatura nacional concernente ao assunto no período investigado, em razão de ter se restringido aos periódicos científicos de nível superior da área de administração. A ideia foi realizar um mapeamento sobre a recente produção científica brasileira de primeira linha acerca das compras públicas estratégicas. Assim, publicações de anais, teses, dissertação e livros não foram consideradas, o que pode configurar uma limitação desta revisão.

Conforme o diagnóstico desvelado nesta revisão, a fim de abranger com maior propriedade e de forma holística toda a complexidade abrangida pelas compras estratégicas, há grandes oportunidades para o emprego de métodos pouco utilizados no campo (abordagem quantitativa ou multimétodos, triangulação de técnicas de coleta e análise de dados e pesquisas no terceiro setor). Há espaço, também, para o desenvolvimento e a validação de uma escala para operacionalizar a variável pesquisada, haja vista a escassez na literatura e a subsequente oportunidade para o desenvolvimento de estudos relacionais e de diagnóstico. Por fim, a realização de pesquisas que confirmem as competências (e explorem outras) para realçar a vertente estratégica da função de compras no setor público são importantes e necessárias para consolidação do tema, a qual pode inspirar sua implementação efetiva na gestão pública organizacional.

Tais recomendações pretendem contribuir para construção de um arcabouço teórico mais consistente que efetivamente promova o avanço progressivo do conhecimento sobre as compras estratégicas nas organizações públicas brasileiras.

\section{Referências}

AMANN, M. et al. Driving sustainable supply chain management in the public sector: The importance of public procurement in the European Union. Supply Chain Management: An International Journal, v. 19, n. 3, p. 351$366,2014$.

ARLBJØRN, J. S.; FREYTAG, P. V. Public procurement vs private purchasing: Is there any foundation for comparing and learning across the sectors? International Journal of Public Sector Management, v. 25, n. 3, p. 203-220, 2012.

ASCHHOFF, B.; SOFKA, W. Innovation on demand: Can public procurement drive market success of innovations? Research Policy, v. 38, n. 8, p. 1235-1247, 2009.

BERGMAN, M. A.; LUNDBERG, S. Tender evaluation and supplier selection methods in public procurement. 
Journal of Purchasing \& Supply Management, v. 19, n. 2, p. 73-83, 2013.

BRASIL. Painel de Compras do Governo Federal. . [S.1.]: https://paineldecompras.planejamento.gov.br/. , 2017

BRATT, C. et al. Assessment of criteria development for public procurement from a strategic sustainability perspective. Journal of Cleaner Production, v. 52, p. 309-316, 2013.

BURGESS, K.; SINGH, P. J.; KOROGLU, R. Supply chain management: A structured literature review and implications for future research. International Journal of Operations \& Production Management, v. 26, n. 7, p. 703-729, 2006.

CABRAL, S.; REIS, P. R. DA C.; SAMPAIO, A. DA H. Determinantes da participação e sucesso das micro e pequenas empresas em compras públicas: Uma análise empírica. Revista de Administração, v. 50, n. 4, p. 477$491,2015$.

CALDAS, E. DE L.; NONATO, R. S. Compras públicas e promoção do desenvolvimento local. Revista do Serviço Público, v. 64, n. 4, p. 465-480, 2013.

CARDOSO, R. F. Um estudo sobre os resultados da utilização da Bolsa Eletrônica de Compras no Governo do Estado de São Paulo. Revista do Serviço Público, v. 55, n. 4, p. 31-44, 2014.

CARR, A. S.; PEARSON, J. N. The impact of purchasing and supplier involvement on strategic purchasing and its impact on firm's performance. International Journal of Operations \& Production Management, v. 22, n. 9, p. 1032-1053, 2002.

CARR, A. S.; SMELTZER, L. R. An empirically based operational definition of strategic purchasing. European Journal of Purchasing \& Supply Management, v. 3, n. 4, p. 199-207, 1997.

CARR, A. S.; SMELTZER, L. R. The relationship among purchasing benchmarking, strategic purchasing, firm performance, and firm size. Journal of Supply Chain Management, v. 35, n. 4, p. 51-60, 1999.

CARTER, J. R.; NARASIMHAN, R. Is purchasing really strategic? International Journal of Purchasing \& Materials Management, v. 32, p. 20-28, 1996.

CHEN, I. J.; PAULRAJ, A.; LADO, A. A. Strategic purchasing, supply management, and firm performance. Journal of Operations Management, v. 22, n. 5, p. 505-523, 2004.

COOPER, M. C.; ELLRAM, L. M. Characteristics of supply chain management and the implications for purchasing and logistics strategy. International Journal of Logistics Management, v. 4, n. 2, p. 13-24, 1993.

COUTO, H. L. G. DO; RIBEIRO, F. L. Objetivos e desafios da política de compras públicas sustentáveis no Brasil: A opinião dos especialistas. Revista de Administração Pública, v. 50, n. 2, p. 331-343, 2016

CRESWELL, J. W. et al. Advanced mixed methods research designs. In: TASHAKKORI, A.; TEDDLIE, C. (Org.). . Handbook of mixed methods in social and behavioral research. 1st. ed. Thousand Oaks: Sage, 2003. p. 209-240.

CRONIN, P.; RYAN, F.; COUGHLAN, M. Undertaking a literature review: A step-by-step approach. British Journal of Nursing, v. 17, n. 1, p. 38-43, 2008.

DEMO FIUZA, G. Desenvolvimento e validação da escala de percepção de políticas de gestão de pessoas (EPPGP). Revista de Administração Mackenzie, v. 9, n. 6, p. 77-101, 2008.

EDLER, J.; GEORGHIOU, L. Public procurement and innovation: Resurrecting the demand side. Research Policy, v. 36, n. 7, p. 949-963, 2007.

ELLRAM, L. M.; CARR, A. S. Strategic purchasing : A history and review of the literature. International Journal of Purchasing \& Materials Management, v. 30, n. 2, p. 10-18, 1994.

FARIA, E. R. DE et al. Fatores determinantes na variação dos preços dos produtos contratados por pregão eletrônico. Revista de Administração Pública, v. 44, n. 6, p. 1405-1428, 2010.

FARMER, D. Developing purchasing strategies. Journal of Purchasing \& Materials Management, v. 14, p. 6-11, 1978.

FERNANDES, R. C. Privado porém público: O terceiro setor na América Latina. Rio de Janeiro: RelumeDumará, 1994.

FIUZA, E. P. S.; MEDEIROS, B. A. DE. A agenda perdida das compras públicas: Rumo a uma reforma abrangente da lei de licitações e do arcabouço institucional. , Texto para Discussão., $\mathrm{n}^{\circ}$ 1990. Rio de Janeiro: 
[s.n.], 2014.

FLICK, U. Qualidade na pesquisa qualitativa. Porto Alegre: Artmed, 2009.

FREEMAN, V. T.; CAVINATO, J. L. Fitting purchasing to the strategic firms: Frameworks, PROCE. Journal of Supply Chain Management, v. 26, n. 1, p. 6-10, 1990.

FREITAS, M. DE; MALDONADO, J. M. S. DE V. O pregão eletrônico e as contratações de serviços contínuos. Revista de Administração Pública, v. 47, n. 5, p. 1265-1282, 2013.

FREITAS, R. K. V. DE; DACORSO, A. L. R. Inovação aberta na gestão pública: Análise do plano de ação brasileiro para a Open Government Partnership. Revista de Administração Pública, v. 48, n. 4, p. 869-888, 2014.

GADDE, L. E.; HÅKANSSON, H. The changing role of purchasing: Reconsidering three strategic issues. European Journal of Purchasing \& Supply Management, v. 1, n. 1, p. 27-35, 1994.

GLOCK, C. H.; HOCHREIN, S. Purchasing organization and design: A literature review. Business Research, v. 4, n. 2, p. 149-191, 2011.

GOMES, F. P.; ARAÚJO, R. M. DE. Pesquisa quanti-qualitativa em administração: Uma visão holística do objeto em estudo. Seminários em Administração, v. 8, p. 1-11, 2005.

JOHNSON, P. F.; LEENDERS, M. R.; MCCUE, C. P. A comparison of purchasing's organizational roles and responsibilities in the public and private sector. Journal of Public Procurement, v. 3, n. 1, p. 57-74, 2003.

JOHNSTON, J. M.; GIRTH, A. M. Government contracts and "managing the market": Exploring the costs of strategic management responses to weak vendor competition. Administration \& Society, v. 44, n. 1, p. 3-29, 2012.

KISER, G. E. Elements of purchasing strategy. Journal of Purchasing \& Materials Management, v. 12, n. 3, p. 37, 1976.

LENFERINK, S.; TILLEMA, T.; ARTS, J. Towards sustainable infrastructure development through integrated contracts: Experiences with inclusiveness in Dutch infrastructure projects. International Journal of Project Management, v. 31, n. 4, p. 615-627, 2013.

MACHADO-DA-SILVA, C. L.; CUNHA, V. C.; AMBONI, N. Organizações: O estado da arte da produção acadêmica no Brasil. 1990, [S.l: s.n.], 1990. p. 11-28.

MATTHEWS, D. Strategic procurement in the public sector: A mask for financial and administrative policy. Journal of Public Procurement, v. 5, n. 3, p. 388-399, 2005.

MCCUE, C. P.; ROMAN, A. E-procurement: Myth or reality? Journal of Public Procurement, v. 12, n. 2, p. 212 $238,2012$.

MENEZES, R. DO A.; SILVA, R. B. DA; LINHARES, A. Leilões eletrônicos reversos multiatributo: Uma abordagem de decisão multicritério aplicada às compras públicas brasileiras. Revista de Administração Contemporânea, v. 11, n. 3, p. 11-33, 2007.

MOGRE, R.; LINDGREEN, A.; HINGLEY, M. Tracing the evolution of purchasing research: Future trends and directions for purchasing practices. Journal of Business \& Industrial Marketing, v. 32, n. 2, p. 251-257, 2017.

MONCZKA, R. M. Integrating purchasing and corporate strategy. 1992, [S.l: s.n.], 1992. p. 1-6.

MOREIRA, M. F.; VARGAS, E. R. DE. Quando o governo é o mercado: Compras governamentais e inovação em serviços de software. Revista de Administração e Inovação, v. 9, n. 2, p. 175-197, 2012.

MURRAY, J. G. Local government and private sector purchasing strategy: A comparative study. European Journal of Purchasing \& Supply Management, v. 7, n. 2, p. 91-100, 2001.

MURRAY, J. G. Local government demands more from purchasing. European Journal of Purchasing \& Supply Management, v. 5, n. 1, p. 33-42, 1999.

MURRAY, J. G.; RENTELL, P. G.; GEERE, D. Procurement as a shared service in English local government. International Journal of Public Sector Management, v. 21, n. 5, p. 540-555, 2008.

NARASIMHAN, R.; DAS, A. The impact of purchasing integration and practices on manufacturing performance. Journal of Operations Management, v. 19, n. 5, p. 593-609, 2001.

NOLLET, J.; BEAULIEU, M. Should an organisation join a purchasing group? Supply Chain Management: An 
International Journal, v. 10, n. 1, p. 11-17, 2005.

OLIVEIRA, B. C. S. C. M. DE; SANTOS, L. M. L. DOS. Compras públicas como política para o desenvolvimento sustentável. Revista de Administração Pública, v. 49, n. 1, p. 189-206, 2015.

PATRUCCO, A. S. et al. Designing a public procurement strategy: Lessons from local governments. Public Money \& Management, v. 37, n. 4, p. 954-962, 2017.

PAULRAJ, A.; CHEN, I. J.; FLYNN, J. Levels of strategic purchasing: Impact on supply integration and performance. Journal of Purchasing \& Supply Management, v. 12, n. 3, p. 107-122, 2006.

PEARSON, J. N.; GRITZMACHER, K. J. Integrating purchasing into strategic management. Long Range Planning, v. 23, n. 3, p. 91-99, 1990.

PIMENTA, C. C. Gestión de compras y contrataciones gubernamentales. RAE eletrônica, v. 1, n. 1, p. 1-13, 2002.

RECK, R. F.; LONG, B. G. Purchasing: A competitive weapon. Journal of Supply Chain Management, v. 24, n. 3, p. 2-8, 1988 .

SILVA, R. C. DA; BARKI, T. V. P. Compras públicas compartilhadas: A prática das licitações sustentáveis. Revista do Serviço Público, v. 63, n. 2, p. 157-175, 2012.

SMITH, J. et al. Balancing competing policy demands: The case of sustainable public sector food procurement. Journal of Cleaner Production, v. 112, p. 249-256, 2016.

SOARES, L. L.; VICENTE, E. F. R. Divulgação das compras públicas de alimentos para a merenda escolar em municípios catarinenses. Gestão \& Regionalidade, v. 27, n. 80, p. 30-44, 2011.

SPEKMAN, R. E. A strategic approach to procurement planning. Journal of Purchasing \& Materials Management, v. 25, n. 1, p. 3-10, 1989.

SPEKMAN, R. E.; HILL, R. P. Strategy for effective procurement in the 1980s. Journal of Purchasing \& Materials Management, v. 16, n. 1, p. 2-6, 1980.

SPEKMAN, R. E.; KAMAUFF, J. W.; SALMOND, D. J. At last purchasing is becoming strategic. Long Range Planning, v. 27, n. 2, p. 76-84, 1994.

TEIXEIRA, M. G. C.; AZEVEDO, L. P. A agenda ambiental pública: Barreiras para a articulação entre critérios de sustentabilidade e as novas diretrizes na administração pública federal brasileira. Revista Eletrônica de Administração, v. 19, n. 1, p. 139-164, 2013.

TRIDAPALLI, J. P.; FERNANDES, E.; MACHADO, W. V. Gestão da cadeia de suprimento do setor público: Uma alternativa para controle de gastos correntes no Brasil. Revista de Administração Pública, v. 45, n. 2, p. 401433, 2011.

UYARRA, E.; FLANAGAN, K. Understanding the innovation impacts of public procurement. European Planning Studies, v. 18, n. 1, p. 123-143, 2010.

WALKER, H.; HARLAND, C. E-procurement in the United Nations: Influences, issues and impact. International Journal of Operations \& Production Management, v. 28, n. 9, p. 831-857, 2008.

WATERMAN, J.; MCCUE, C. P. Lean thinking within public sector purchasing department: The case of the UK public service. Journal of Public Procurement, v. 12, n. 4, p. 505-527, 2012.

WATTS, C. A.; KIM, K. Y.; HAHN, C. K. Linking purchasing to corporate competitive strategy. International Journal of Purchasing \& Materials Management, v. 31, n. 1, p. 2-8, 1995.

WHITE, G. R. T. et al. Challenges to the development of strategic procurement: A meta-analysis of organizations in the public and private sectors. Strategic Change, v. 25, p. 285-298, 2016.

ZHENG, J. et al. An analysis of research into the future of purchasing and supply management. Journal of Purchasing \& Supply Management, v. 13, n. 1, p. 69-83, 2007. 